\title{
Study of Knowledge, Skill and Extent of Participation of Self Help Group Members in Managing SHGs and Income Generating Activities
}

\author{
N. Khoisnam* and S.D. Mukhopadhyay \\ Department of Agricultural Extension, Institute of Agriculture, Visva-Bharati, \\ Sriniketan, India \\ *Corresponding author
}

\begin{tabular}{|l|}
\hline K e y w o r d s \\
SHG, Impact, Income \\
Generating activities, \\
Enterprise, Vocation, \\
Empowered, \\
Correlation \\
\hline Article Info \\
\hline $\begin{array}{l}\text { Accepted: } \\
\text { 16 December } 2017 \\
\text { Available Online: } \\
\text { 10 January } 2018\end{array}$ \\
\hline
\end{tabular}

A B S T R A C T
120 SHG members from 12 SHGs of Haorangsable and Wangoi block of Imphal-West district of Manipur were studied. Majority of the respondents were of middle age, married, belonging to general caste, living in nuclear and small family, having low education and residing in 'Pucca' houses with 'service' as their primary occupation while SHG is the secondary one, possessing less than 1 acre of land with semi-medium to low level of social participation and extension contact; possessing negligible land and household possession were mostly above Rs. 1, 00,000. Respondent's knowledge on guidelines of SHG and record keeping were found to be comparatively higher after joining SHG. Skill competencies were of semi-medium level $(83.33 \%)$. Extent of participation in incomegenerating and SHG activities were found to be at high level and majority $(66.66 \%)$ of the respondents were highly empowered by the existing vocation undertaken by the SHGs. Results also revealed that some of the independent variables like, age, social participation, family size, land holding and cosmopoliteness had significant positive correlation with the extent of knowledge, skill competency and extent of participation of members in income generating activities. Family annual income was found to have negatively significant relationship with extent of empowerment.

\section{Introduction}

Self Help Group (SHG) is a small voluntary association of poor people, mainly women, preferably from the same socio - economic background. They come together for the purpose of solving their common problems, especially economic problems through selfhelp and mutual help. The limit of members of the group is restricted in between 10-20 because any group bigger than this would need to be registered under the Society
Registration Act. Groups are expected to be homogeneous so that the members do not have conflicting interests and all the members can participate freely without any fear (Kumari and Sehrawat, 2011). It is universally accepted that women's income in the family is very much essential and important in relation to nutritional, economical and educational upliftment of the family. But, for the centuries, women have been neglected to a secondary status in the family as well as in society compared to their male counterpart when they 
constitute about $48.46 \%$ of the total population of India (Provisional Census Report, 2011). The concept of Self Help Groups gained significance especially after 1976 when Prof. Mohammed Yunus of Bangladesh began experimenting with microcredit and Women Self Help Groups.

The strategy made a revolution in Bangladesh towards poverty eradication by empowering the poor women (CIRDAP Development Digest, 2000). Keshava et al., (2010) reported in their study that working in group fulfills all the requirements of economic activity i.e. from arrangement of raw materials required for production up to marketing of the final product. Amutha, (2011) in her study conducted in Tamil Nadu revealed that the most important motivating factor for the women to join in SHGs was to supplement their family income and improve the economic contribution to family. Lalitha and Prasad, (2011) also reported in their study that though the women have formed SHGs, they have poor decision making capacity for their selfdevelopment. In this backdrop the present study has been attempted with the broad objective study the knowledge, skill and extent of participation of Self Help Group members in managing SHGs and income generating activities in Imphal-West district of Manipur. The Specific objectives of the present research work are as follows:

To study socio-economic and socio-personnel attributes of the Self Help Group members;

To study the extent of change in knowledge and skill of the SHG members in different SHG activities;

To study the extent of participation of SHG members in managing SHGs and income generating activities and extent of empowerment of members through SHG activities

\section{Materials and Methods}

The study was conducted in the Haorangsable block and Wangoi block of Imphal-West district of Manipur. The area of the study is comprised of six Gram Panchayats, three each from both the blocks viz. from Haorangsable block- Sagolband Thounaojam Leikai, Sagolband Sapam Leikai, and Takyel and from Wangoi block- Malom, Sangaiprou Mamang and Heinoukhongnembi. Two SHGs from each Gram Panchayat having at least twenty respondents each have been studied. Proper scientific procedures of selecting the district, blocks, SHGs and respondents have been followed. Thus in total 120 respondents (taking 20 respondents from each six SHGs) were selected. The collected data was codified, tabulated, classified and further categorized for the systematic statistical analysis. The statistical tools used were such as mean, frequency, percentage, standard deviation, index value and correlation. The Index Value for each determinant was calculated by following the formula (Das, 2012; Moktan and Mukhopadhyay, 2012).

Index Value $=\{$ Score obtained $/$ Score Max $X$ $100\}$

Index value (ranging from 0-100) was classified into four different class intervals, like low (with value 0-25), Semi-Medium (2650), Medium (51-75) and High (with index value 76-100).

\section{Results and Discussion}

The findings of the present study have been presented below in different sub-sections.

\section{Socio-economic and socio-personnel attributes of the Self Help Group members}

Socio economic profile of women respondents were studied through their age, education, 
marital status, caste, family type, family size, house type, social participation, cosmopoliteness, extension contact, occupation, household possessions and annual income from SHGs etc. The results are presented in Table 1.

From Table 1, it can be found that majority of the respondents belonged to the middle age (55\%) group followed by old age $(28.33 \%)$ group having mean 44.4 and SD 9.66. Majority of them were married followed by widow $(11.66 \%) .90 \%$ of the respondents were found to belong in general caste and only $10 \%$ were found to be OBC. Majority of the respondents live in nuclear family $(85.83 \%)$ followed by joint family (14.16\%) with 3-5 members $(69.16 \%)$ followed by family having 6-9 members $(28.33 \%)$ having mean value of 4.7 and SD 1.23. The above findings are similar with the findings of Chitagubbi et al., (2011) which reported majority of the SHG respondents belong to age group of 36-45 years, married, general caste and nuclear family. Results of respondent, levels of education shows that $44.16 \%$ of them had high school level of education followed by middle elementary level of education (39.16\%) having mean value of 10.1 and SD 3.07. When taking family's education of the respondents it was found that majority of the respondents family $(50 \%)$ were having high school level followed by $(29.16 \%)$ having middle elementary level of education (Mean 9.8 and SD 2.44).

So far housing pattern was concerned majority of them were having (60\%) pucca houses while $(40 \%)$ were having mixed house structure. Majority of the respondents (43\%) were having service as primary occupation while $88.33 \%$ of them taken up SHG activities as secondary occupation and rest taken up SHG as tertiary occupation. Majority of the respondents $(100 \%)$ were having up to 1 acre of land as poverty prevalence and less purchasing power among the respondents (Mean 0.05 and SD 0.02). About $64.16 \%$ of the respondents belonged to more than Rs. $1,00,000 /-$ of the household article possession group followed by $15 \%$ of the respondents possessed household articles worth of Rs. 50,001/- 60,000/- (Mean Rs. 108126.3 and SD Rs. 45170.89).

In case of digital communication material possessed by respondents it was found that majority of the respondents $(31.66 \%)$ uses mobile as communication material followed by $(22.5 \%)$ radio. A two way measurement of extent of social participation of the respondents was done through calculation of index by following the formula as given in methodology section and respondents were distributed over four class intervals namely, low (index 0-25), Semi-Medium (26-50), Medium (index 51-75) and high (76-100). The results are presented in the table. Firstly, respondents were asked to mention their status of membership in different organisations and institution and secondly, their extent of visit to different organisation and institutions were also taken into consideration.

The Table 1 reveals that 100 per cent of the respondents belonged to low level of Social Participation (membership in different organisations / institutions) with Mean 13.3 and SD 5.32. This in turn was followed by semi-medium and low level of extent of their visit to different organisations / institutions with 68.33 per cent and 31.66 per cent respectively (Mean 30.0 and SD 8.83). It was also found that majority of the respondents $(46.66 \%)$ were visiting outside village once in a month followed by $(25.83 \%)$ once in a week. About 100 per cent of the respondents belonged to low level of contact with extension agent (Mean 14.2 and SD 4.58). 41.6 per cent of the respondents belonged to the income group having earnings up to Rs. $1,00,000$ annually followed by 36.66 per cent 
with Rs. 1,00,001- Rs. 1,50,000 annually (Mean Rs.119441.7 and SD Rs. 55030). In case of total family income (Inclusive of all sources of all family members) it was found that majority of the respondents $(74.16 \%)$ having total annual family income to the tune of more than Rs. 2,00,000 followed by more than Rs.1,50,001 to Rs. 2,00,000 (16.66\%) (Mean Rs. 260897.6 and SD Rs. 88891.43).

\section{Extent of change in knowledge and skill of} the SHG members in different SHG activities

\section{Extent of knowledge gained about SHG}

For ascertaining the extent of change in knowledge of the SHG members in different SHG activities "Before-After" research design was used. Eleven aspects of SHG activities have been identified for the purpose, like Concept of SHG, Objective of SHG, Formation of SHG, Functioning of SHG, Vocation selection, Accounting, Report and return, Memorandum and bye-laws of SHG, Meeting details, Vocational activities and Record maintenance. Respondents were asked to mention their knowledge against each eleven statements in a three point continuum (Hardikar, 1998) containing 'fully known' (with corresponding score of 2), 'partially known' (with corresponding score of 1) and 'not known' (with corresponding score of 0) respectively for before and after joining SHG. Knowledge Index (KI-1) for each respondent was calculated by using the formula as mentioned above in the methodology. The distribution of respondents according to their Knowledge Index is presented in Table 2 in four class intervals.

The results reveal that the respondents had low and semi-medium $(79.16 \%$ and $20.83 \%$ respectively) level of knowledge about SHG before joining the SHG. But after joining SHGs it was found that all the members $(100 \%)$ obtained high level of knowledge about different activities of SHGs. The results speak in favour of the positive impact of SHGs in improving the knowledge of its members about different activities of SHGs. It also establishes the participatory mode of operation of SHGs.

\section{Extent of knowledge gained about record keeping in SHG}

For ascertaining the extent of change in knowledge in record keeping of the SHG members "Before-After" research design was used as it was done in earlier section. Ten aspects of SHG activities have been identified for the purpose pertinent to record keeping, like, Stock and store, Meeting register, Cash book, Receipt book, Payment register, Bank account, Loan register, Audit of accounts etc. Respondents were asked to mention their knowledge about record keeping against each ten statements as mentioned above in three point scale for before and after joining SHG. Knowledge Index (KI-2) for each respondent was calculated by using the formula as mentioned in the methodology. The distribution of respondents according to their Knowledge Index is presented in Table 2 in four class intervals.

It is revealed from the table that respondents were having low $(92.5 \%)$ and medium $(7.5 \%)$ level of knowledge on record before joining SHG. But after joining SHGs the level of knowledge of record keeping of the respondents has been changed largely and it was found that respondents were having high $(51.66 \%)$ and medium (48.33\%) level of knowledge of record keeping. The finding therefore shows the positive impact of SHGs in acquiring overall knowledge required for running the SHGs by the respondents. This finding is also supported by Varghese (2016) which reported the positive impact of record keeping among the members of SHG in Ramsai Hills, Assam. 
Skill competency in managing the enterprise

For ascertaining the extent of change in knowledge of the SHG members in different SHG activities same "Before-After" research design was used. Ten aspects of SHG activities have been identified for the purpose, like, Input requirement, Production technology, Feeding/ nutrient management, Infrastructure development, Plant protection/ health care, Harvesting, Post harvesting, Value addition, Marketing of the produce, Equipment and machinery required, Day to day management, Grading/ packaging, Grinding, Pickle/ jam/ jelly preparation, Kantha stitching, Tailoring and Handicraft. Respondents were asked to mention their knowledge about skill competency against each eighteen statements as mentioned above in a three point scale for before and after joining SHG.

Skill competency Index for each respondent was calculated by using the formula as mentioned above in the methodology. The distribution of respondents according to their Knowledge Index is presented in Table 3 in four class intervals.

The study reveals that majority of the respondent belonged to low level (91.66\%) followed by semi-medium level (8.33\%) of skill competency in managing the enterprise before joining the SHG. Further the study shows majority of the respondent were upgraded to semi-medium (83.33\%) followed by medium (16.66\%) level of skill competency in managing the enterprise after joining the SHG. The above findings are in conformity with the findings of Sharma et al., (2012) which reported that SHGs are becoming one of the important means for the empowerment of poor women in all developing countries including India. He observed a medium change in knowledge, skill and attitude was observed after training.
Extent of participation of SHG members in managing SHGs and income generating activities and extent of empowerment of members through SHG activities

\section{Extent of participation in income- generating activities}

For ascertaining the extent of participation in income-generating activities for official work of SHG, four aspects of SHG activities have been identified for the purpose, like, Attending meetings, Keeping accounts, Keeping records, Maintaining bank liason. Respondents were asked to mention their participation against each four statements in a three point continuum containing 'regularly' (with corresponding score of 2), 'sometimes' (with corresponding score of 1) and 'never' (with corresponding score of 0) (Hardikar, 1998) respectively. Participation Index for each respondent was calculated by using the formula as mentioned above in the methodology. The distribution of respondents according to their Participation Index (PI-1) is presented in Table 4 in four class intervals.

The data reveals that $(60 \%)$ of the respondents belonged to high level of participation for official work of SHG followed by (33.33\%) of the respondent belonged to medium and (6.66\%) semi-medium level of participation for official work of SHG category.

\section{Extent of participation for production purpose}

For ascertaining the extent of participation in income-generating activities for production purpose of SHG, five aspects of SHG activities have been identified for the purpose, like, Procurement of raw materials, Cleaning, Grading, Processing and Final production. Respondents were asked to mention their participation against each five statements as mentioned above. 
Table.1 Distribution of respondents according to their Socio-economic and psychological and socio-personnel attributes of the SHG members and their relation with overall knowledge level

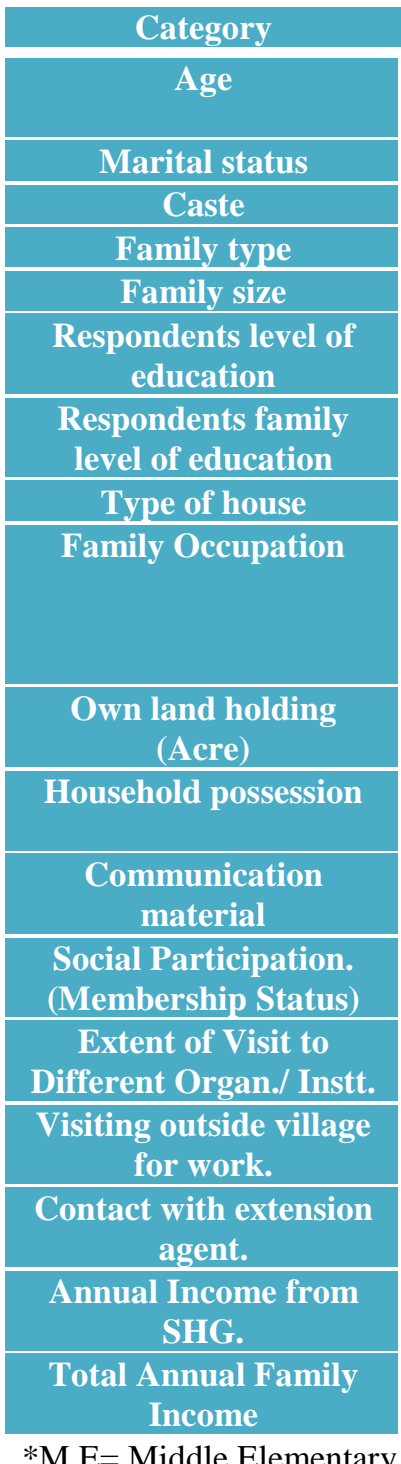

\begin{tabular}{|c|c|}
\hline$(\%)$ & Major 2 \\
\hline 55 & $\begin{array}{c}\text { Old -Above 50 } \\
\text { years }\end{array}$ \\
\hline 83.33 & Widow \\
\hline 90 & OBC \\
\hline 85.83 & Joint \\
\hline 69.16 & $6-9$ members \\
\hline 44.16 & M.E School \\
\hline 50 & M.E School \\
\hline 60 & Mixed \\
\hline 43.33 & $\begin{array}{c}\text { Primary (Business) } \\
\text { Secondary } \\
\text { (Service) }\end{array}$ \\
\hline 100 & \begin{tabular}{c} 
Tertiary (SHG) \\
\hline
\end{tabular} \\
\hline
\end{tabular}

Up to 1 acre

\begin{tabular}{|c|}
\hline Above \\
\hline Rs. $1,00,000 /-$ \\
\hline Mobile
\end{tabular}

Low $(0-25)$

Semi-Medium (2650)

$$
100
$$

\begin{tabular}{|c|c|}
\hline 64.16 & $\begin{array}{c}\text { Rs. } 50001 /- \text { to } \\
60000 /-\end{array}$ \\
\hline 31.66 & Radio \\
\hline
\end{tabular}

100

68.33

Low $(0-25)$

Low $(0-25)$

\section{Rs. 50,001/-to $1,00,000 /-$}

Above

Rs.2,00,000/-

46.66 Once in a week

\begin{tabular}{|c|c|c|}
\hline$(\%)$ & Mean & S.D \\
\hline 28.33 & 44.4 & 9.66 \\
\hline
\end{tabular}

$11.66 \quad$ Categorical data

10 Categorical data

14.16 Categorical data

\begin{tabular}{|l|l|l|}
\hline 28.33 & 4.7 & 1.23 \\
\hline 39.16 & 10.1 & 3.06 \\
\hline
\end{tabular}

\begin{tabular}{|l|l|l|}
\hline 39.16 & 10.1 & 3.06 \\
\hline
\end{tabular}

\begin{tabular}{|l|l|r|}
\hline 29.16 & 9.8 & 2.43 \\
\hline
\end{tabular}

$40 \quad$ Categorical data

$40.83 \quad$ Categorical data

8.33

0

\begin{tabular}{|c|c|c|} 
& 0.05 & 0.025 \\
\hline 15 & 108126.3 & 45170.89 \\
\hline
\end{tabular}

22.5 Categorical data

\begin{tabular}{|l|r|r|}
\hline & 13.3 & 5.32 \\
\hline 31.66 & 30.0 & 8.83 \\
\hline
\end{tabular}

$25.83 \quad$ Categorical data

\begin{tabular}{|l|l|l|l|l|}
\hline 100 & - & - & 14.2 & 4.58 \\
\hline
\end{tabular}

\begin{tabular}{|c|c|c|c|c|}
\hline 41.66 & $\begin{array}{c}\text { Rs.1,00,001/-to } \\
1,50,000 /-\end{array}$ & 36.66 & 119441.7 & 55030 \\
\hline 74.16 & $\begin{array}{c}\text { Rs. } 1,50,001 /- \text { to } \\
2,00,000 /-\end{array}$ & 16.66 & 260897.6 & 88891.43 \\
\hline
\end{tabular}

*M.E $=$ Middle Elementary, S.D = Standard Deviation.

Table.2 Extent of Knowledge about SHG among the respondents

\begin{tabular}{|c|c|c|c|c|c|c|c|c|}
\hline \multirow{2}{*}{ Knowledge Index } & \multicolumn{3}{|c|}{ Knowledge about SHG } & \multicolumn{3}{c|}{ Knowledge about Record Keeping } \\
\cline { 2 - 10 } & \multicolumn{2}{|c|}{$\begin{array}{c}\text { KI-1 } \\
\text { (Before) }\end{array}$} & \multicolumn{2}{c|}{$\begin{array}{c}\text { KI-1 } \\
\text { (After) }\end{array}$} & \multicolumn{2}{c|}{$\begin{array}{c}\text { KI-2 } \\
\text { (Before) }\end{array}$} & \multicolumn{2}{c|}{$\begin{array}{c}\text { KI-2 } \\
\text { (After) }\end{array}$} \\
\hline & F & P & F & P & F & P & F & P \\
\hline 0-25 (Low) & 95 & 79.16 & 0 & 0 & 111 & 92.5 & 0 & 0 \\
\hline $\mathbf{2 6 - 5 0}$ (Semi-Medium) & 25 & 20.83 & 0 & 0 & 9 & 7.5 & 0 & 0 \\
\hline 51-75 (medium) & 0 & 0 & 0 & 0 & 0 & 0 & 58 & 48.33 \\
\hline $76-100$ (High) & 0 & 0 & 120 & 100 & 0 & 0 & 62 & 51.66 \\
\hline
\end{tabular}

*K.I= Knowledge Index, $\mathrm{F}=$ Frequency, $\mathrm{P}=$ Percentage. 
Int.J.Curr.Microbiol.App.Sci (2018) 7(1): 2270-2279

Table.3 Skill competency in managing enterprise

\begin{tabular}{|c|c|c|c|c|}
\hline \multirow{2}{*}{ Skill competency in SHG } & \multicolumn{3}{|c|}{ Before } & \multicolumn{2}{c|}{ After } \\
\hline & Frequency & Percentage & Frequency & Percentage \\
\hline $\mathbf{0 - 2 5}$ (Low) & 110 & 91.66 & 0 & 0 \\
\hline $\mathbf{2 6 - 5 0}$ (Semi-Medium) & 10 & 8.33 & 100 & 83.33 \\
\hline $\mathbf{5 1 - 7 5}$ (Medium) & 0 & 0 & 20 & 16.66 \\
\hline $76-100$ (High) & 0 & 0 & 0 & 0 \\
\hline
\end{tabular}

Table.4 Extent of participation in official work of SHG and empowerment through existing vocation of the members

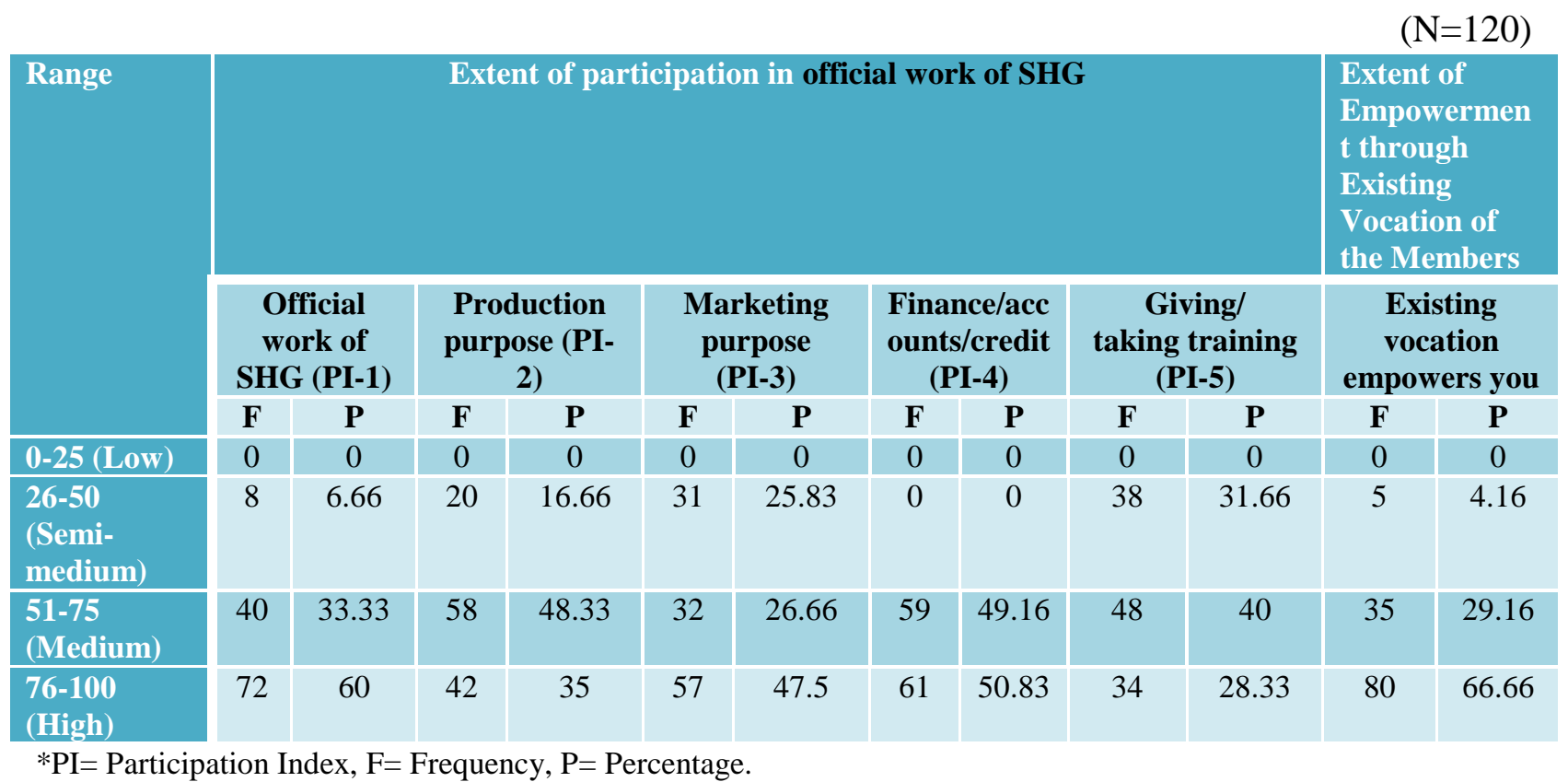

*PI= Participation Index, F= Frequency, P= Percentage.

Table.5 Correlation between different independent variables with extent of knowledge, skill and participation in SHG and income generating activities

\begin{tabular}{|c|c|c|c|c|c|c|c|c|c|c|c|}
\hline & $X_{1}$ & $X_{2}$ & $\mathbf{X}_{3}$ & $\mathbf{X}_{4}$ & $X_{5}$ & $X_{6}$ & $X_{7}$ & $\mathbf{X}_{8}$ & $X_{9}$ & $\mathbf{X}_{10}$ & $\mathbf{X}_{11}$ \\
\hline $\mathbf{Y}_{1}$ & 0.142 & -0.003 & 0.094 & 0.075 & -0.040 & 0.022 & $0.189 * *$ & 0.089 & -0.009 & -0.035 & -0.035 \\
\hline $\mathbf{Y}_{2}$ & $0.192 * *$ & $0.199 * *$ & -0.088 & 0.074 & 0.126 & 0.104 & -0.026 & -0.015 & -0.088 & -0.085 & -0.085 \\
\hline$Y_{3}$ & 0.005 & 0.126 & 0.063 & 0.130 & $0.191 * *$ & 0.103 & 0.051 & 0.052 & -0.043 & 0.002 & 0.002 \\
\hline $\mathbf{Y}_{4}$ & -0.018 & 0.088 & -0.016 & -0.029 & 0.028 & 0.039 & 0.040 & -0.040 & 0.088 & 0.072 & 0.072 \\
\hline$Y_{5}$ & 0.049 & 0.047 & 0.057 & 0.036 & 0.079 & 0.099 & 0.121 & $0.212 * *$ & 0.104 & 0.044 & 0.044 \\
\hline $\mathbf{Y}_{6}$ & -0.010 & -0.027 & 0.006 & -0.009 & 0.115 & -0.129 & -0.007 & -0.021 & -0.090 & $0.190 * *$ & $\begin{array}{l}-0.193 \\
* *\end{array}$ \\
\hline $\mathbf{Y}_{7}$ & $0.197 * *$ & 0.040 & -0.027 & 0.089 & 0.008 & 0.111 & $0.190 * *$ & 0.065 & 0.060 & -0.041 & -0.041 \\
\hline$Y_{8}$ & $-0.193 * *$ & 0.059 & 0.065 & -0.056 & -0.049 & -0.024 & 0.141 & 0.004 & 0.037 & 0.019 & 0.019 \\
\hline$Y_{9}$ & -0.076 & -0.070 & 0.076 & 0.017 & 0.008 & -0.008 & 0.032 & -0.036 & -0.099 & -0.061 & -0.061 \\
\hline
\end{tabular}

Table Value of r @ 118 degrees of freedom @ 5\% level -- 0.189 and @ 1\% level -- 0.247 
Participation Index for each respondent was calculated by using the formula as mentioned above in the methodology. The distribution of respondents according to their Participation Index (PI-2) is presented in Table 4 in four class intervals. The data reveals that $(48.33 \%)$ of the respondents belonged to medium level of participation for production purpose of SHG followed by $(35 \%)$ of the respondent belonged to high and (16.66\%) semi-medium level of participation for production purpose of SHG category.

\section{Extent of participation for marketing purpose}

For ascertaining the extent of participation in income-generating activities for marketing purpose of SHG, five aspects of SHG activities have been identified for the purpose, like, Packing, Labelling, Sending to market, Retailing and Promotion of product. Respondents were asked to mention their participation against each five statements as mentioned in the above. Participation Index for each respondent was calculated by using the formula as mentioned above in the methodology. The distribution of respondents according to their Participation Index (PI-3) is presented in Table 4 in four class intervals.

The data reveals that $(47.5 \%)$ of the respondents belonged to high level of participation for marketing purpose of SHG followed by $(26.66 \%)$ of the respondent belonged to medium and $(25.83 \%)$ semi-medium level of participation for marketing purpose of SHG category.

\section{Extent of participation for finance/accounts/credit purpose}

For ascertaining the extent of participation in income-generating activities for finance/accounts/credit purpose of SHG, five aspects of SHG activities have been identified for the purpose, like, Collection and membership fee, Taking offer for getting credit from bank, arrangement for finance for production, Maintenance of accounts and Bank transaction. Respondents were asked to mention their participation against each five statements as mentioned above. Participation Index for each respondent was calculated by using the formula as mentioned above in the methodology. The distribution of respondents according to their Participation Index (PI-4) is presented in Table 4 in four class intervals.

The data reveals that $(50.83 \%)$ of the respondents belonged to high level of participation for Finance/accounts/credit purpose of SHG followed by (49.16\%) of the respondent belonged to medium level of participation for Finance/accounts/credit purpose of SHG category.

\section{Extent of participation for giving/taking training purpose}

For ascertaining the extent of participation in income-generating activities for giving/taking training purpose of SHG, two aspects of SHG activities have been identified for the purpose, like, Giving training to members and Attending training for knowledge/ skill development. Respondents were asked to mention their participation against each two statements as mentioned in the above. Participation Index for each respondent was calculated by using the formula as mentioned above in the methodology. The distribution of respondents according to their Participation Index (PI-5) is presented in Table 4 in four class intervals.

The data reveals that $(40 \%)$ of the respondents belonged to medium level of participation for Giving/taking training purpose of SHG followed by $(31.66 \%)$ of the respondent belonged to semi-medium and $(28.33 \%)$ high level of participation for Giving/taking training purpose of SHG category.

\section{Existing vocation helps/empower the SHG members}

For ascertaining how far the existing vocation helps/empower the SHG members, twelve 
aspects of SHG activities have been identified for the purpose, like, Independency in living, Relate to the past experience, Remunerative, Better education to children, Utilization of leisure time, Self-empowered, Provide monthly fixed income, System competency, Utilization of available resources, Contribute significantly to family, Socio culturally acceptable and any others. Respondents were asked to mention their level of empowerment against each twelve statements in a three point continuum containing 'strongly agree' (with corresponding score of 3), 'agree' (with corresponding score of 2) and 'disagree' (with corresponding score of 1) (Hardikar, 1998) respectively. Empowerment Index for each respondent was calculated by using the formula as mentioned above in the methodology. The distribution of respondents according to their Empowerment Index is presented in Table 4 in four class intervals.

The data reveals that $(66.66 \%)$ of the respondents belonged to high level of existing vocation empower of SHG members followed by $(29.16 \%)$ of the respondent belonged to medium and $(4.16 \%)$ semi-medium level of existing vocation empower of SHG member's category.

\section{Relationship between different independent variables with extent of knowledge, skill and participation in SHG and income generating activities}

At the last stage correlation co-efficient were calculated taking dependent variables such as Extent of knowledge gained about SHG $\left(\mathrm{Y}_{1}\right)$, Extent of knowledge gained about record keeping in SHG $\left(\mathrm{Y}_{2}\right)$, Skill competency in managing the enterprise $\left(\mathrm{Y}_{3}\right)$, Extent of participation for official work of SHG in income-generating activities $\left(\mathrm{Y}_{4}\right)$, Extent of participation for production purpose $\left(\mathrm{Y}_{5}\right)$, Extent of participation for marketing purpose $\left(\mathrm{Y}_{6}\right)$, Extent of participation for finance/accounts/credit purpose $\left(\mathrm{Y}_{7}\right)$, Extent of participation for giving/taking training purpose $\left(\mathrm{Y}_{8}\right)$, Existing vocation helps/empower the SHG members $\left(\mathrm{Y}_{9}\right)$ with independent variables like
Age $\left(\mathrm{X}_{1}\right)$, Family size $\left(\mathrm{X}_{2}\right)$, Respondents level of education $\left(\mathrm{X}_{3}\right)$, Respondents family level of education $\left(\mathrm{X}_{4}\right)$, Own land holding (acre) $\left(\mathrm{X}_{5}\right)$, Household possession $\left(\mathrm{X}_{6}\right)$, Social participation (Membership status) $\left(\mathrm{X}_{7}\right)$, Extent of visit to different organ./ instt. $\left(\mathrm{X}_{8}\right)$, Contact with extension agent $\left(\mathrm{X}_{9}\right)$, Annual income from SHG $\left(\mathrm{X}_{10}\right)$ and Total annual family income $\left(\mathrm{X}_{11}\right)$.

The results are presented in the Table 5. It is found from the table that most of the independent variables are having positive corelation with the independent variables. Only in case of Extent of participation for marketing purpose $\left(\mathrm{Y}_{6}\right)$ most of the independent variables were found to have negative co-relation. However, Extent of knowledge gained about SHG $\left(\mathrm{Y}_{1}\right)$ was found to have positive and significant correlation with Social participation (Membership status $X_{7}$ ); while Extent of knowledge gained about record keeping in SHG $\left(\mathrm{Y}_{2}\right)$ was found to have positive and significant correlation with Age $\left(\mathrm{X}_{1}\right)$ and Family size $\left(\mathrm{X}_{2}\right)$. Skill competency in managing the enterprise $\left(\mathrm{Y}_{3}\right)$ had positive and significant correlation with Own land holding $\left(\mathrm{X}_{5}\right)$ and Extent of participation for production purpose $\left(\mathrm{Y}_{5}\right)$ had positive and significant correlation with Extent of visit to different organ./ instt. $\left(\mathrm{X}_{8}\right)$. Extent of participation for marketing purpose $\left(\mathrm{Y}_{6}\right)$ was found to have positively significant relationship with Annual income from SHG $\left(\mathrm{X}_{10}\right)$ but Total annual family income $\left(\mathrm{X}_{11}\right)$ was fund to have negatively significant relationship. Extent of participation for finance/accounts/credit purpose $\left(\mathrm{Y}_{7}\right)$ had positively significant relationship with Age $\left(\mathrm{X}_{1}\right)$ and Social participation (Membership status) $\left(\mathrm{X}_{7}\right)$. In case of Extent of participation for giving/taking training purpose $\left(\mathrm{Y}_{8}\right)$, Age $\left(\mathrm{X}_{1}\right)$ was found to have negatively significant relationship.

From this study it can be concluded that majority of the respondents were married and mostly middle aged having low education and resides in pucca houses. Majority of the primary source of respondent's family income comes from service and have land holding below 1 acre. The participation of the respondents in 
SHGs has enhanced them in their household possession, income, knowledge on guidelines about SHG, record keeping and also their skill competency towards managing enterprises.

They have also extended their level of participation in income-generating activities after joining SHG which in return empowered them through their existing vocation undertaken by the SHG.

From the results it can be summarised that SHGs had a positive impact on the members in terms of gaining knowledge and skills for different SHG and income generating activities. It can also be concluded that some of the socioeconomic and socio-personal variables, like, age, social participation, land holding, extent of visit to different organisation / institution, annual income from SHGs were having positive and significant relationship with the extent of improvement in knowledge, skills and participation in different SHG and income generating activities.

\section{References}

Amutha, D. 2011. An analysis of economic empowerment of women SHGs in Tuticorin District. Journal of Advances in Development Research, 2(2): 227-32.

Chitagubbi, G., Shivalli, R. and Devendrappa, S. 2011. A study on the usefulness of Self Help Group membership to women for empowerment. Journal of Farm Sciences, 1(1): 112-119.

CIRDAP Development Digest. 2000. Various issues, Bangladesh

Das, E.P.K. 2004. Participation of Rural Women in Agricultural Operation. Indian
Research Journal of Extension Education, 4(1\&2): 142-145

Hardikar, D.P. 1998. Perfection of development programme derived by women beneficiaries of Ratnagiri District, Unpublished Ph.D Thesis, University of Dhawrad.

Keshava, Mehta, A.K. and Gill, H.K. 2010. Management of Economic Activity in Women Self Help Groups. Indian Research Journal of Extension Education, 10(1): 58-61.

Kumari, S. and Sehrawat, R.K. 2011. Can Self Help Groups Generate Employment Opportunity for Rural Poor? European Journal of Social Science, 19(3): 371379.

Lalitha, K. and Prasad, G. 2011. Impact of Women Empowerment and Role of SHGs in Value based Emancipation. Indian Streams Research Journal (ISRJ), 1(II): 130-133.

Moktan, M.W., and Mukhopadhyay, S.D. 2012. Nature and extent of participation of farm women and their economic contribution in agriculture- a case study in hilly district of West Bengal. Indian Research Journal of Extension Education, 12 (2).

Sharma, Roy, A., Bikash and Chakarvorty, D. 2012. Potential of Self Help Groups as an Entrepreneur: A Case Study from Uttar Dinajpur District of West Bengal. Journal of Social Sciences, 30(1): 83-87.

Varghese, O. 2016. Empowerment of Women through Self-help Groups and Credit Linkage: A Case Study of Six Self-help Groups under Ramsai Hills, Assam. The Journal of North East Indian Cultures, JNEIC. 3: 94.

\section{How to cite this article:}

Khoisnam, N. and Mukhopadhyay, S.D. 2018. Study of Knowledge, Skill and Extent of Participation of Self Help Group Members in Managing SHGs and Income Generating Activities. Int.J.Curr.Microbiol.App.Sci. 7(01): 2270-2279. doi: https://doi.org/10.20546/ijcmas.2018.701.275 